\title{
LA FACTICIDAD DE LA FILOSOFÍA POLÍTICA DE FRANCISCO SUÁREZ: UN CAMINO HACIA OTRA MODERNIDAD*
}

\author{
PABLO FONT OPORTO \\ Universidad Loyola Andalucía
}

\begin{abstract}
RESUMEN: Es posible defender que el pensamiento político de Suárez se halla en tránsito desde lo medieval a una Modernidad diferente. El núcleo de dicha interpretación es la tesis de que la consecución del bien común inserto en la facticidad de la realidad humana concreta es el motor de la teoría política suareciana. Desde ahí se analizan sus elementos fundamentales: primero, el origen comunitario del poder político a partir de la naturaleza social de la persona, creada así por Dios. Segundo, la articulación operativa de dicho poder a través de su entrega absoluta a un gobernante y la preferencia (relativa) por la Monarquía como forma de gobierno. Tercero, la aceptación de la resistencia al tirano en determinados casos y condiciones. Así, cabe sostener que la flagrante contradicción entre la translatio total del poder político y la simultánea admisión de la resistencia a este supone, en última instancia, negar la primera, erigir esta última como límite del poder, y abrir la puerta a un modelo de democracia directa.
\end{abstract}

PALABRAS CLAVE: bien común; origen del poder político; democracia; límites del poder político; derecho de resistencia; desobediencia civil; tiranicidio; Modernidad; tradición ignaciana; facticidad; Francisco Suárez.

\section{Facticity in Francisco Suárez' political philosophy: a path to another Modernity}

ABSTRACT: It is possible to sustain that Suárez's political thinking is in transit from Middle Ages to a different Modernity. The core of this interpretation is this thesis: The motor of the Suarezian political theory is the achievement of the common good inserted in the facticity of the concrete human reality. Based on these premises, the principal elements of this theory are analysed here. Firstly, the community origin of political power, which originates from the base of the social character of human beings, created in this way by God. Secondly, the operational articulation of that power, through the absolute transfer to a ruler and the (relative) preference towards Monarchy as form of government, according to Suárez. Thirdly, the acceptance of the resistance to tyranny in certain cases and conditions. Therefore, one can understand that the flagrant contradiction between the total translatio of political power and the simultaneous admission of resistance means to reject the first, to proclaim the last as a limit to power, and open the possibility to a model of direct democracy.

KEY WORDS: common good; origins of political power; democracy; limits of political power; right of resistance; civil disobedience; tyrannicide; Modernity; Ignatian tradition; facticity; Francisco Suárez.

\section{INTRODUCCIÓN. AsPECTOS MEDIEVALES Y DE MODERNIDAD DIFERENTE}

Partimos de la tesis que sostiene que en el pensamiento suareciano en general, y en el político en particular, hay elementos medievales, modernos, y otros que

Este artículo se enmarca dentro del Proyecto I+D+I «Pensamiento y tradición jesuita y su influencia en la Modernidad desde las perspectivas de la Historia, la Traductología y la Filosofía Jurídica, Moral y Política» (PEMOSJ), financiado por el Ministerio de Economía y Competitividad del Gobierno de España y el Fondo Europeo de Desarrollo Regional (MINECO/FEDER) (referencia FFI2015-64451-R), y cuyo investigador principal es el Prof. Dr. Juan Antonio Senent de Frutos. 
no cabe encuadrar del todo en ninguna de esas etiquetas. A estos últimos los incluimos en lo que podría denominarse un tipo de Modernidad diferente. En este sentido, diversos autores, partiendo de distintos paradigmas explicativos, coinciden en que en Suárez se aprecian rasgos de una Modernidad diferente a partir de la confluencia en su obra de diversas tradiciones que divergen de la Modernidad hegemónica ${ }^{1}$. Al respecto, cabe advertir que la tradición que sigue Suárez es, de un lado, la tradición ignaciano-jesuita ${ }^{2}$ y, de otro, la propia de la escuela ibérica ${ }^{3}$.

De acuerdo con estos presupuestos, el propósito de este trabajo es mostrar una panorámica general de la teoría política de Suárez e intentar constatar si, de acuerdo con las premisas de partida, es posible defender que el pensamiento político de Suárez se halla en tránsito desde lo medieval a una Modernidad diferente.

Por otro lado, hay que indicar que este trabajo se centra en los tratados Defensio fidei y De legibus, ya que son obras de madurez en las que el profesor jesuita recoge la esencia de su Filosofía política (aunque Suárez tiene otras obras específicas de pensamiento político y, además, trata cuestiones de este ámbito en otras obras). Al respecto, hay que advertir que mientras Defensio fidei es una obra de circunstancias, cuya redacción se ve obligado a emprender como encargo papal en el contexto de la polémica del juramento de fidelidad del rey Jacobo I de Inglaterra, De legibus es un tratado sistemático meditado largamente en el que aborda todo lo relativo a la ley humana, divina y natural ${ }^{4}$.

\section{Encuadre general de la filosofía POLÍtica de SuÁREZ}

El pensamiento suareciano es un sistema construido coherentemente, desde una espiritualidad, una Teología y una Metafísica determinadas. En efecto, como ya hemos defendido anteriormente ${ }^{5}$, el moderado nominalismo de la metafísica de Suárez, unido a los rasgos particulares de las tradiciones de pensamiento en que este autor se inserta, le lleva a conceder gran peso a los entes concretos, a las realidades particulares. De tal forma que su Filosofía práctica

1 Domingues (1997), pp. 202 y 205-207; Dussel (2007a), pp. 17-44; Dussel (2007b), p. 223, de la Torre Rangel, pp. 195-223; Rosillo Martínez (2011), p. 28; Senent de Frutos (2010); Senent de Frutos (2014); Senent de Frutos (2017). En este sentido, desde esa convergencia, cabe advertir que no hay una originalidad completa en muchas de las tesis de Suárez.

2 Font Oporto (2014); Senent de Frutos (2014).

3 Calafate y Mandado GutiérRez (2014), pp. 110-155. Todas estas cuestiones, en general, las hemos desarrollado en Font OpORTo (2014).

4 En general, y salvo algunos cambios, se han seguido las traducciones de la colección Corpus Hispanorum de Pace, editadas por el CSIC.

5 Vid. Font Oporto (2013a); Font Oporto (2014); Font Oporto (en prensa). 
se centra en «lo concreto, lo variado, lo plural, lo múltiple y lo contingente», en definitiva, «lo histórico en la vida humana ${ }^{6}$, lo que desemboca en un prisma casuista y posibilista ${ }^{7}$.

Más en concreto, en su filosofía política ese «más vivo sentido de lo existente concreto y de los entes singulares» mueve a Suárez a conceder gran autonomía a las "causas segundas», lo que permite un fuerte inmanentismo del poder político con relación a toda la comunidad perfecta y, de este modo, una concepción más democrática (si bien no en el sentido moderno liberal). Por otro lado, la aproximación suareciana al objeto jurídico suele ser moral y se concreta en la aplicación de un enfoque casuista y probabilista ${ }^{8}$.

En efecto, Suárez se enfrenta a la realidad como un objeto poliédrico e intenta por tanto ajustar una solución para cada caso, haciendo comprender al lector la importancia de los matices presentes en cada supuesto9. De este modo, la atención al caso concreto le posibilita alcanzar soluciones complejas fuertemente aferradas a la realidad. Es lo que anteriormente ya hemos denominado, de forma tentativa, "facticidad suareciana» ${ }^{10}$. Pues bien, el peso de esa facticidad en la filosofía práctica suareciana, unido a la centralidad del bien común como telos y fundamento de la vida en común del ser humano es, a nuestro juicio, el punto esencial donde, a partir de elementos medievales, Suárez construye elementos que, siendo ya en parte modernos, difieren en sus caracteres de la versión hegemónica de la Modernidad.

6 Elorduy (1952), p. 88; Cabral de Moncada (1948), pp. 235-236. En la cuestión de la voluntad de Dios se suele clasificar a Suárez como un ecléctico cuyas ideas se hallan en un equilibrio intermedio entre el tomismo puro y el escotismo u ockahmismo puro (así por ejemplo, vid. Cabral de Moncada (1948), pp. 232-233).

7 De esta forma, la Filosofía práctica de Suárez se caracteriza por la primacía de «la existencia sobre la esencia, de lo singular concreto sobre lo general-abstracto, y del Derecho natural dominativo sobre el natural preceptivo, en función de la casuística de las situaciones históricas» (propter materiae variatione, en palabras de Suárez) (CABRAL DE MonCADA, 1948, p. 239; traducción propia del original portugués). Cabe defender que la elección de dichos planteamientos metafísicos está condicionada por las líneas de tradición que sigue Suárez, esto es, de un lado, la tradición ignaciano-jesuita y, de otro lado, la propia de la escuela ibérica, aunque es una cuestión que está aún por desarrollar.

8 Cabral de Moncada (1948), pp. 236-238.

9 Esto no significa que no trate siempre de alcanzar posiciones universalmente justificables, racionales y admitidas por cualquiera.

10 Vid. Font Oporto (2013a); Font Oporto (2013b); Font Oporto (2014); Font Oporto (2017a); Font Oporto, (en prensa). No debe confundirse la facticidad suareciana con el realismo maquiavélico, con el tacitismo o con el organicismo naturalista conservador. 
2. LA TEORÍA DEL PODER POLÍTICO EN SUÁREZ

\subsection{Presupuestos antropológicos de la teoría suareciana del poder político: la sociabilidad natural humana en el origen de la comunidad política}

La teoría del poder político de Suárez, enmarcada en la corriente iusnaturalista predominante en la Escuela ibérica, echa sus raíces en el carácter natural de dicho poder y parte de un concepto de persona como ser social por naturaleza, que tiende a vivir en comunidad y que necesita a esta para su conservación ${ }^{11}$. No sólo eso: "por la naturaleza misma de las cosas» esas comunidades humanas que surgen a resultas de la naturaleza social humana tienden a desbordar los lazos familiares y a convertirse por tanto en comunidades políticas ${ }^{12}$.

Juan Carlos Scannone defiende que en la visión suareciana toda comunidad humana es política y jurídica desde el inicio, si bien a un nivel sub-estatal. Para este autor, Suárez considera que, en estas primeras construcciones, cuando gozan de unidad moral y van más allá de un mero aglomerado de familias, ya existe un elemento contractual y voluntario (y por tanto jurídico, podríamos añadir). Al respecto, Suárez distingue entre la comunidad humana política y el mero agregado de personas, y sostiene la necesidad del poder político en la comunidad política ${ }^{13}$.

11 Vid. De legibus, III, I, 2, 3 y 12; Defensio fidei, III, I, 4. Para Suárez «la condición natural del hombre consiste en ser animal social y exigir por naturaleza una forma de vida comunitaria que debe ser gobernada necesariamente por el poder político» (De legibus, III, I, 12). Se trata este de un concepto aristotélico por otra parte muy común en el pensamiento de origen escolástico. Suárez cita expresamente a Aristóteles en Defensio fidei (III, I, 4), De legibus (III, I, 2 y 3) y De opere sex dierum (V, VII, 5), en la que recoge la afirmación de que el hombre es "por naturaleza un animal civil y social».

12 Cfr. De legibus, III, I, 3. Para Suárez la comunidad familiar es insuficiente para realizar de manera íntegra al ser humano, que de este modo tiende naturalmente a buscar una forma superior de vida. «La razón es que ninguna familia puede reunir dentro de sí todos los medios y servicios necesarios para el desarrollo de la vida humana» (De legibus, III, I, 3). Más adelante afirma Suárez que «el poder político no empezó a existir hasta que empezaron a asociarse en una sola comunidad perfecta varias familias» (De legibus, III, II, 3).

13 Señala Scannone que la acentuación de la libertad y «la necesidad del consenso voluntario» en Suárez «no presupone una antropología individualista de la libertad, que sólo ulteriormente se hace social por medio de un pacto. Por el contrario, el hombre naturalmente libre es asimismo natural y necesariamente social y político, aunque forma parte de esta o de otra comunidad política determinada en forma libre e histórica» (SCANnONE (1999), p. 242). Parece, pues, que en el origen de la comunidad política en Suárez hay un equilibrio entre naturaleza social del ser humano y libre consentimiento manifestado en el pacto. De este modo, sostenemos que las visiones exclusivamente contractualistas de Suárez no parecen ajustarse a la realidad, como tampoco las exclusivamente organicistas (sobre esto último, vid. Schwartz Porzecanski (2005), p. 120 y ss.). 


\subsection{El origen del poder político en Suárez}

La doctrina de Suárez sobre el origen de la comunidad y el poder político va a fundamentar la existencia y el ejercicio legítimo de dicho poder.

\subsubsection{El poder político como necesidad, su legitimidad en abstracto y su confor- midad con la naturaleza humana}

En un primer análisis abstracto del poder político, Suárez sostiene que éste es necesario para la conservación de la propia comunidad política (la cual es, a su vez, precisa para la conservación del ser humano): se requiere la existencia de un gobernante al que se le preste obediencia para dirigir a ese cuerpo hacia el bien común ${ }^{14}$. De este modo, Suárez no sólo conecta ya la cuestión de la conservación de la comunidad con la necesidad del bien común, sino que señala la promoción del mismo como la tarea del poder.

\subsubsection{La residencia natural del poder en la comunidad, resultado de la configu-} ración de la naturaleza humana por Dios

Para Suárez el poder reside por naturaleza en la propia comunidad. La razón es que el poder surge de la constitución libre y voluntaria de una comunidad política por parte de sujetos por naturaleza iguales. Siendo esos sujetos, pues, iguales y libres por naturaleza, el poder no reside en unos por encima de otros, antes bien, es propiedad de la comunidad en su conjunto. Además, esa residencia en la comunidad se reafirma por la finalidad que impulsa el nacimiento tanto de la comunidad política como del poder: el bien común. En efecto, si la finalidad del poder interesa y afecta a todos los miembros de la comunidad, es lógico que originariamente el poder sea una propiedad compartida por todos los sujetos insertos en la misma.

Por otra parte, puesto que Dios es el creador del ser humano, cuya naturaleza le impulsa a unirse en comunidades políticas donde brota el poder político como necesario, y dicho poder es además propiedad esencial de la comunidad, donde reside por naturaleza, para Suárez el poder político es otorgado por Dios directamente a la comunidad, donde existe además en orden a dar respuesta a la finalidad para la que surge: el bien común. Por tanto, el poder se asienta en la comunidad por voluntad de Dios. En conclusión: el poder brota de la comunidad política, pero es Dios quien lo establece ahí (porque la naturaleza humana, individual y comunitaria, es obra divina) ${ }^{15}$.

14 Defensio fidei, III, I, 4 y 8; De legibus, III, I, 2-5.

15 Ambas cuestiones, la procedencia divina del poder político y su residencia natural originaria en la comunidad son tratadas por Suárez conjuntamente pues fundamenta recíprocamente ambas, una en la otra. En particular, este tema aparece en Defensio fidei, III, I y II; así como en De legibus, III, II y III). 
En efecto, Suárez defiende que «primeramente el supremo poder político [...] fue conferido por Dios a los hombres unidos en la ciudad [civitatem] o comunidad política perfecta [...] por natural consecuencia y en fuerza de su creación [de los hombres]. Por eso, en virtud de esta manera de donación, no reside este poder [político] en una [sola] persona ni en un grupo determinado de muchas personas, sino en la totalidad perfecta del pueblo o cuerpo de la comunidad ${ }^{16}$. Agrega Suárez en defensa de ese carácter «natural» del poder político, que dicho poder surge de la propia constitución de la comunidad política: «por el mismo hecho de congregarse los hombres en un cuerpo o comunidad política [reipublicae], resulta [resultat] dicho poder en esta comunidad sin intervención de ninguna voluntad creada». Esto es prueba de que ese poder "procede directamente de Dios, con la intervención solamente de la resultancia natural [naturali resultantia] o por consecuencia de la naturaleza y por dictamen que demuestra la razón natural» ${ }^{17}$.

Ahora bien, ¿cuál es el papel de la voluntad individual de cada uno de los miembros de la comunidad de cara al surgimiento del poder? Dice Suárez que «ese poder no resulta en la naturaleza humana hasta que los hombres se agrupan en una comunidad perfecta y se unen políticamente», pues «ese poder no se da en los individuos separadamente considerados ni tampoco en la masa o multitud ${ }^{18}$. De este modo, si bien el poder es una propiedad que Dios ha dispuesto en la naturaleza humana reunida en comunidad, es preciso el consentimiento (como expresión de la libre voluntad personal) de cada uno de sus miembros para la constitución de esa comunidad. Pero, como puede verse, para Suárez el papel de la voluntad humana en el surgimiento del poder político es limitado, pues «esa voluntad sólo es necesaria para constituir una comunidad perfecta», dado que en la misma

16 Defensio fidei, III, II, 5; cfr. también De legibus, III, II, 4; De legibus, III, III, 5.

17 Defensio fidei, III, II, 6. La utilización por parte de Suárez, aquí y en otros pasajes (como De legibus, III, III, 5), de este término resultantia (y también la expresión resultat, en alusión al surgimiento del poder en la comunidad «sin intervención de ninguna voluntad creada») parece remitirnos al concepto metafísico suareciano de la acción de resultancia (Sergio Rábade habla de "causalidad por resultancia»). Una ajustada definición puede hallarse en la página web de la Biblioteca Saavedra Fajardo de Pensamiento Político Hispánico (AA.VV., s. a.): «consiste esta acción en que el hombre, en el aspecto gnoseológico y en otras actividades humanas, no es la causa total, ni siquiera la principal, de las empresas que acomete. La acción de resultancia en la que intervienen multitud de causas, empezando por el concurso natural y sobrenatural, etc., es la base de todo el mundo moral, en la que Suárez señala la confluencia de nuestra acción con la acción divinohumana variadísima que aparece no sólo en la creación primera, sino en la evolución creativa». Con la «resultancia» o "acción de resultancia», Suárez amplía los cuatro modos clásicos de causalidad admitidos comúnmente desde Aristóteles. Sobre el concepto de causalidad vid. Pérez Espigares et al. (en prensa); también BarRoso Fernández (2008), p. 24; RÁbAde (1997), pp. 24-25; ElorduY (1963); Abril Castelló (1978); Scannone (1999), pp. 250-251.

18 De legibus, III, III, 6; De legibus, III, II, 4. 
el poder político «resulta de la naturaleza de las cosas y de la providencia del autor de la naturaleza» ${ }^{19}$.

\subsection{Articulación operativa del poder político en Suárez: la translatio imperii desde la comunidad al gobernante. Supeditación de la forma de gobierno al bien común como fin del poder político}

Suárez distingue la cuestión del origen del poder político de la relativa a la configuración operativa del mismo, cuestión esta última que suele tratar después de la primera

\subsubsection{La democracia como forma natural de gobierno, pero no inmutable}

Después de afirmar la natural residencia originaria del poder en toda la comunidad política, Suárez sostiene, sin embargo, que la articulación efectiva del poder político exige una configuración operativa para que éste pueda efectivamente actuar para el bien común de aquella. Al respecto, Suárez explica la existencia de diferentes posibilidades a la hora de estructurar ese poder, pero opta por preferir la entrega del poder a un sujeto determinado (monarquía), de tal modo que éste reciba el encargo de ejercer el poder político de la comunidad. Ahora bien, el hecho de que el poder del monarca proceda directamente de la comunidad supone que el poder de dicho rey tiene un origen divino sólo en un sentido mediato o indirecto, lo cual comporta dos consecuencias.

Un primer corolario sería que la monarquía no es la forma natural del poder. De lo cual cabe colegir que «en virtud de la sola razón natural el poder político [principatus politicus] no se determina» necesariamente "a la monarquía o a la aristocracia pura o mixta, porque no existe ninguna razón que demuestre que es necesario esta forma concreta de gobierno $»^{20}$. De esta manera, Suárez sostiene que la forma de gobierno natural es la democracia, puesto que el poder se da en la comunidad de modo natural.

Ahora bien, Suárez entiende que puesto que «el poder político [principatus politicus] es de Derecho natural», en el sentido de que no es una creación directa establecida por Derecho divino, sino indirecta como consecuencia de la naturaleza humana, la forma de gobierno es un ámbito que está sujeto a la libre voluntad humana ${ }^{21}$. En esta cuestión, como en otras muchas, puede percibirse en Suárez la preponderancia de la voluntad sobre la naturaleza ${ }^{22}$. De

19 De legibus, III, III, 6. Por tanto, el pacto no interviene en el surgimiento del poder (pues dicho surgimiento es espontáneo conforme a la naturaleza humana, de la cual resulta), sino tan solo (como se verá a continuación) en la posterior articulación operativa del poder, que (salvo en el caso de que se mantuviese una democracia directa) se entrega a un sujeto o un grupo de sujetos para su ejercicio efectivo.

20 Defensio fidei, III, II, 7.

21 Defensio fidei, III, I, 7; vid. también ibidem, 9.

22 Vid. también De legibus, III, III, 7. 
este modo, Suárez entiende que residencia natural del poder no es inmutable y distingue, por tanto, entre forma de gobierno natural y forma de gobierno positiva o instituida por la voluntad humana ${ }^{23}$. Es más, este autor no se decanta por la democracia como forma de gobierno positiva o instituida, sino que muestra su predilección por la monarquía ${ }^{24}$, si bien muestra cierta flexibilidad sobre la cuestión ${ }^{25}$. Esa flexibilidad de la organización del poder en Suárez es, a nuestro juicio, resultado de la supeditación de la misma al fin último de aquel: el bien común. Así lo confirma el propio Suárez al afirmar que «el poder ha sido conferido por la naturaleza y su autor en condiciones tales que pueda ser modificado como mejor convenga al bien común» ${ }^{26}$. Esto supone una apertura definitiva de su teoría y una clara señal de cómo ha de ser interpretada.

\subsubsection{La posibilidad de que la comunidad se despoje absolutamente de su poder original. Polémicas analogías}

A priori, una segunda consecuencia del origen comunitario del poder del monarca (o lo que es lo mismo, del hecho de que no lo reciba directamente de Dios), estriba en que dicho poder es revocable y limitable. Sin embargo, Suárez no extrae esas consecuencias en su teoría del poder político. Y no es fácil determinar si en dicha aparente contradicción juegan un importante papel la realidad preponderante en su contexto histórico o las presiones de los conflictos políticos teórico-prácticos en que se halla envuelto (tales como la disputa sobre el juramento de fidelidad de Jacobo I de Inglaterra).

De acuerdo con la mencionada posibilidad que la voluntad humana tiene de configurar el poder político, sostiene nuestro autor que «aun cuando ese poder sea como una propiedad natural de la comunidad perfecta de los hombres en cuanto tal, sin embargo, no se da en ella de manera inmutable, sino que se puede privar a la comunidad del poder por su propio consentimiento o por cualquier otro procedimiento justo y transferirlo a otro titular» ${ }^{27}$.

Suárez intenta demostrarlo mediante un ejemplo que suscita hoy en día encendidas críticas: la analogía con el caso de la esclavitud voluntaria, que el profesor jesuita acepta en el caso del sujeto individual. La explicación de este paralelismo que resulta hoy día absolutamente anacrónico es que, aunque

\footnotetext{
${ }^{23}$ Vid. Defensio fidei, III, II, 8.

24 «La razón natural dictamina que no es necesario — ni aun conveniente- a tal naturaleza mantener inmutable ese poder en toda la comunidad», puesto que a su juicio "considerado así el poder y sin el complemento de una determinación o la realización de algún cambio, apenas sería posible ejercer el poder» (De legibus, III, III, 8). Como puede verse, en esta última afirmación se hace presente el elemento histórico contextual de Suárez, que en parte orienta la afirmación anterior, más abierta y flexible, hacia su horizonte históricocultural conocido (en el que no aparece la posibilidad de una democracia operativa). Ahora bien, esa orientación no llega a cercenar del todo las virtualidades de su visión general flexible.

${ }_{25}$ Cfr. Defensio fidei, III, I, 5.

26 De legibus, III, III, 8.

27 De legibus, III, III, 7.
} 
«ser libre de la esclavitud [servitute] es una propiedad natural del hombre» ${ }^{28}$, el Derecho natural «no prohíbe absolutamente que un hombre sea reducido a servidumbre», sino "únicamente que esto se haga sin el libre consentimiento del hombre o sin un justo título y poder [sine iusto titulo et potestatem] ${ }^{29}$. De donde a contrario deduce Suárez que «por su propia voluntad el hombre puede abdicar de su libertad e incluso ser privado de ella por una causa justa y ser reducido a la esclavitud» ${ }^{30}$. Para Suárez, «algo parecido ocurre con la comunidad humana perfecta», la cual, «aunque por naturaleza sea libre y tenga poder sobre sí misma, puede verse privada del poder [...] por su propio consentimiento o por cualquier otro procedimiento justo» ${ }^{31}$ "por quien tenga para ello un título justo y poder [legítimo], y [puede] ser transferido [el poder político de la comunidad] a una persona determinada o a un senado» ${ }^{32}$.

Ahora bien, pese al claro anacronismo medievalizante que encontramos aquí, es preciso, sin embargo, conforme a la hipótesis mantenida en este trabajo, preguntarse si en esta analogía sólo hay restos medievales o puede haber trazas de alguna explicación que inserte la misma en la línea de una transición hacia otro tipo de Modernidad. En este sentido, debe afirmarse que es necesario una interpretación de dicha analogía de la esclavitud voluntaria que logre una cierta conciliación de la misma con el tratamiento de los límites en la teoría política en Suárez, especialmente en lo que respecta a la posibilidad de la resistencia y desobediencia civil. En este sentido, defendemos que Suárez acepta la esclavitud voluntaria de la persona, igual que la de la comunidad, porque entiende que no puede negarse esa posibilidad en caso de que sea la más beneficiosa para el bien de las mismas. De este modo, por tanto, el autor no se cierra a la posibilidad de que ciertas instituciones puedan existir, siempre que se justifiquen en el bien común, el cual se erige aquí de nuevo en el eje crucial de una teoría del poder caracterizada por un enfoque fáctico (y también, por qué negarlo, en cierto modo pragmático ${ }^{33}$.

Otro ejemplo que Suárez ofrece de posible renuncia al poder recibido de Dios es el de la posible renuncia del papa, que el profesor granadino acepta como posible.

\footnotetext{
28 De legibus, III, III, 7.

29 Defensio fidei, III, II, 9.

30 De legibus, III, III, 7.

31 De legibus, III, III, 7.
}

32 Defensio fidei, III, II, 9. Con las expresiones «cualquier otro procedimiento justo» (De legibus, III, III, 7) y «título justo y poder» (Defensio fidei, III, II, 9) parece que Suárez está aludiendo a los casos de guerra justa, a la que hace referencia expresa en De legibus, III, III, 8.

33 La analogía de la transferencia de poder con el caso de la esclavitud voluntaria es una imagen que más tarde utilizarán también Grocio y Puffendorf (Amezúa AmezúA, 2008, p. 53). Dicha analogía merece, en todo caso, un estudio más profundo que permita entender este ejemplo en Suárez, dada la estridencia que a priori causa en nuestro contexto actual, así como la aparente incoherencia de esta tesis con el resto de la teoría política suareciana. Dicho estudio, que excede absolutamente las posibilidades de este trabajo, requeriría también contextualizar históricamente esta cuestión. Hemos intentado ofrecer algunas claves interpretativas respecto a la misma en FonT OPORTO (2014), capítulo 3. 
Ahora bien, al respecto, para Suárez el poder político es «más dependiente de las voluntades de los hombres» que el poder del papa, de tal modo que, si bien este último sólo puede renunciar libremente, «la comunidad política [respublica]» puede «en ocasiones y por causa justa ser privada de su propia libertad de manera coactiva [per coactionem], como es, por ejemplo, la guerra justa» ${ }^{34}$.

\subsubsection{El pacto de entrega del poder}

Puesto que, como ya hemos visto, Suárez sostiene la entrega directa del poder por parte de Dios a la comunidad, se sigue de aquí que «ningún rey o monarca recibe o ha recibido ([al menos] conforme a la ley ordinaria) el poder político [politicum principatum] directamente de Dios o por institución divina, sino mediante la voluntad y la institución humana» ${ }^{35}$. Es aquí, en el contexto de esta traslación de poder, donde aparece por primera vez el concepto de pacto entre el gobernante y el pueblo: siguiendo a S. Agustín, Suárez afirma que «el poder de los reyes [regium principatum] y la obediencia que se les debe tiene su fundamento en un pacto de la sociedad humana»; por consiguiente, este poder tiene su origen en «la voluntad de los hombres» y la monarquía es una institución humana. No hay, pues, una intervención directa por parte de Dios mediante la que apruebe ese acto de traslación ${ }^{36}$. Para Suárez, el pueblo (populus) por medio de un pacto «trasladó al príncipe [principem] el poder con la carga y obligación de gestionar el gobierno de la comunidad política [gerendi curam reipublicae] y administrar justicia; y el príncipe aceptó tanto el poder como la condición $»^{37}$.

\subsection{El fundamento de la teoría del poder político en Suárez: el bien común}

\subsubsection{Complejidad del concepto de bien común en Suárez}

El concepto de bien común es una idea compleja en Suárez. En primer lugar, porque el propio Suárez da por supuesto su significado y no formula una definición clara y expresa del mismo, al considerar que su manejo por la tradición escolástica es suficiente para comprender su contenido. En segundo lugar, porque, en consonancia con el perfil fáctico de su pensamiento adaptado a la realidad, en el que las circunstancias del caso concreto y las circunstancias humanas (causas segundas, si las distinguimos de las primeras, divinas y naturales) cobran gran importancia, el profesor jesuita parece concebir el bien común como un concepto dinámico y cambiante. En efecto, puesto que el centro de la atención de Suárez es el sujeto (social) y las circunstancias de este (y de la

\footnotetext{
34 De legibus, III, III, 8.

35 Defensio fidei, III, II, 10.

36 Una vez más, el pensamiento del profesor jesuita concede gran importancia a la acción humana como causa segunda.

37 Defensio fidei III, II, 11-13.
} 
comunidad donde se desenvuelve) cambian constantemente, no es posible una concreción inmutable del contenido del bien integral de dicho sujeto y de dicha comunidad. Por otro lado, al ser considerado un sujeto no aislado, sino social (en contraposición a la visión cartesiana y liberal en general), se establecen unas correspondencias entre los bienes de ambos, sujeto y comunidad, que pueden en ocasiones resultar (y más en nuestra mentalidad actual, derivada de la modernidad) harto problemáticas.

\subsubsection{El bien común como fin del poder político}

Suárez afirma que "propiamente el poder político está de suyo ordenado directamente sólo al bienestar y a la felicidad terrenal de la comunidad humana política [humanae reipublicae] para el tiempo de la vida presente, de lo cual toma precisamente el nombre de poder temporal $»^{38}$.

Igualmente, Suárez sostiene que el fin del «poder político legislativo [potestatem civilem legislativam; civilem es usado para distinguirlo del canónico]» es «la felicidad natural de la comunidad humana perfecta cuyo gobierno gestiona [cuis curam gerit] y de cada uno de los hombres en cuanto que son miembros de esa comunidad ${ }^{39}$. Y a continuación Suárez enumera los elementos de esa felicidad cuando indica que dicho poder «mira a que [los miembros de la comunidad] vivan políticamente en paz y justicia, con la abundancia de bienes suficientes para el mantenimiento y el bienestar de su vida material y con la normal rectitud de costumbres que es necesaria para la paz social, la felicidad de la comunidad política [felicitatem reipublicae] y la adecuada conservación de la naturaleza humana». Más adelante, reitera Suárez que el poder político está «esencialmente ordenado al bien común» del «cuerpo místico [corpus mysticum]» que constituye la comunidad «y a su propia felicidad». Y concluye: «en consecuencia, todo aquello que atañe a la felicidad privada, pero sin que redunde en bien de la comunidad, nada tiene que ver con el poder o la ley civil» ${ }^{40}$.

\subsubsection{El bien común como fundamento de la obediencia al poder político}

Sostiene Suárez que una vez constituida la comunidad política la sumisión al poder político es conforme a la recta razón natural, por cuanto dicha sumisión es precisa para la conservación de la propia naturaleza humana ${ }^{41}$. En el mismo pasaje Suárez fundamenta también la legitimidad de la sumisión al poder político

38 Defensio fidei, III, V, 2.

39 De legibus, III, XI, 7.

40 Delegibus, III, XI, 7. Igualmente, en De legibus, I, III, 20 dice Suárez que puede definirse la ley civil o temporal como aquella que va dirigida al gobierno político de la comunidad, a la protección de los derechos temporales [esto es, no espirituales] y al mantenimiento de la comunidad política en paz y justicia.

41 Defensio fidei, III, I, 8. 
en la afirmación de que pese a que la persona haya sido creada como un ser libre, eso no le impide someterse a otra si es «por una causa justa y razonable».

De este modo, sostiene Suárez que «si bien es verdad que el hombre no ha sido creado ni nace sometido al poder de ningún príncipe humano [potestati principis humani]» y, por tanto, la sujeción de «la comunidad política humana» a alguien no es algo que establezca «el propio derecho natural por sí mismo y sin la intervención de la voluntad humana», sin embargo, el ser humano «sí nace potencialmente sujeto, por así decir, a tal poder» y dicha sujeción se halla «muy en consonancia con la razón natural». La explicación es que dicha sujeción es necesaria para la conservación de la comunidad humana derivada de la propia naturaleza social de la persona, cuestión que ya hemos tratado. Por tanto, «no va en contra de ningún precepto del derecho natural» el hecho de que el ser humano «esté sometido de hecho» al poder político, «aunque esta sumisión no deriva directamente de la naturaleza ${ }^{42}$; es decir, que precisa la intervención de la libre voluntad humana.

No obstante, el propio Suárez nos advierte que esta legitimidad in abstracto o a priori del poder político y de la sumisión al mismo nada tiene que ver con la posibilidad de que, por «abuso de los hombres», se constituyan poderes tiránicos.

\section{La Resistencia civil en SuÁrez y el impacto de la misma en SU teoría del Poder}

\subsection{Contradicciones entre la teoría del poder y la teoría de la resistencia en Suárez}

Suárez admite la resistencia al tirano e incluso el recurso al tiranicidio en determinados supuestos y con determinados requerimientos y matizaciones ${ }^{43}$

42 De legibus, III, I, 11.

43 En el tema de la resistencia y el tiranicidio Suárez navega entre una serie de excepciones y contra-excepciones (por ejemplo, en el capítulo IV del Libro VI de la Defensio fidei que concluye con una posición favorable de facto a la limitación del poder merced a la legitimación de la resistencia al tirano sobre la base de diversas fundamentaciones [¿democrática por vía fáctica?]). A nuestro juicio, la secuencia de movimientos favorables y contrarios a la limitación democrática del poder es como sigue: primero, origen del poder político en la comunidad (a favor); segundo, en caso de entrega del poder al soberano, el pacto no es rescindible (en contra), aunque sí cabe introducir limitaciones en la misma (a favor); tercero, cabe el derecho de resistencia al gobernante tirano (a favor); cuarto, no cabe derecho de resistencia si hay pacto (en contra); quinto, incluso en ese caso cabe la resistencia en defensa propia (a favor). Vidal Abril recoge este hilo argumental suareciano en forma más desarrollada: «las precisiones básicas de Suárez respecto a la mutabilidad interna unilateral del régimen vigente son las siguientes: a) Una vez establecido el régimen acordado, el pueblo no tiene poder y autoridad para cambiarlo unilateralmente (suo arbitrio seu quoties voluerit; pro libito, etc.), salvo en los casos y condiciones en que se haya reservado expresamente poder para ello y así conste documentalmente o por vía consuetudinaria. b) Lo establecido obliga estrictamente a las partes, especialmente por tratarse de pactos constitucionales onerosos y condicionantes. c) En casos de tiranía en ejercicio por abuso del poder, la tiranía ha de ser muy cualificada (in manifestam perniciem civitatis), pero entonces lo que entra en juego, 
(hemos tratado esta cuestión en diversos trabajos) ${ }^{44}$. Así, por ejemplo, distingue entre los casos del tirano mal gobernante, al que sólo es posible darle muerte en legítima defensa de la propia vida o de la comunidad, y el tirano usurpador, al que puede matarlo cualquier persona privada de la comunidad con una serie de condiciones ${ }^{45}$. De este modo, por la vía de la excepción de la legítima defensa permite Suárez no sólo la desobediencia, sino incluso la resistencia civil activa, la rebelión y el tiranicidio (en determinados supuestos) aun respecto al monarca con título legítimo que gobierna tiránicamente.

En consecuencia, emerge aquí en Suárez una clara contradicción con los resultados últimos de su teoría del poder. En efecto, la articulación operativa de este último había concluido con la posibilidad de una completa e irrevocable enajenación y entrega por parte de su poseedor originario (la comunidad política) al gobernante en unos términos que suponían la exclusión de cualquier limitación a dicho poder. Lo que, por tanto, a priori, dejaba sin consecuencias y liquidaba de facto la teoría del origen democrático del poder ${ }^{46}$. Sin embargo, es obvio que la aceptación de la resistencia legítima abre una puerta trasera a la limitación del poder del gobernante y a la revocabilidad de la entrega del mismo por parte del pueblo. Y a ello se añade que dichas figuras, pese a estar muy tasadas, tienen en la teoría política de Suárez la última palabra ${ }^{47}$.

Para entender el encaje de estas teorías que a priori parecen contradictorias es fundamental señalar cuál es el fundamento de la aceptación de la resistencia en Suárez. A partir de aquí será posible elaborar una hipótesis (no anacrónica y concorde con su sistema-pensamiento) sobre el papel que la resistencia juega en la teoría política de Suárez ${ }^{48}$.

según Suárez, no es ninguna pretendida soberanía popular —ni siquiera la llamada in habitu—s ino el Derecho natural de legítima defensa que el pueblo nunca puede enajenar (Defensio fidei, III, 3, 2-4)» V. Abril CASTelló (1976), pp. 141 y 142, nota 19.

44 En Font Oporto, 2013a llevamos a cabo una exposición de la esencia del pensamiento suareciano sobre el problema de la resistencia al tirano y su interpretación desde la literatura científica, centrado en particular en Defensio fidei, VI, IV, 1-9. En Font OporTo (2017b) analizamos la discusión de Suárez con las teorías opuestas a la distinción entre los dos tipos de tiranos a la hora de analizar la legitimidad de su occisión, teorías que entienden que no le es lícito a una persona privada matar a ninguno de los dos tipos de tirano: sólo es posible darles muerte en legítima defensa, porque se entiende que en tal caso se actúa en ejercicio de autoridad pública (Defensio fidei, VI, IV, 10-13). En Font Oporto (2017a) estudiamos las posibilidades de desobediencia a los reyes no cristianos y herejes, en aquello que es incompatible con la fe o a la ley injusta. En Font OpORTo (2014) abordamos de manera más amplia y profunda el tema de la resistencia al tirano en Suárez, así como las fuentes de su visión.

45 Vid. Defensio fidei, VI, IV, 1-9.

46 Si bien, ya se defendió que, en principio, dicha entrega total e irrevocable se concibe por parte de Suárez como una posibilidad que está abierta en tanto en cuanto esté ordenada a la consecución del bien común.

47 Cuestión diferente es la de si existen o no en Suárez posibles vínculos entre el origen democrático del poder y la posibilidad de la resistencia popular.

48 Sobre la importancia de entender la obra y el pensamiento de Suárez como un sistema vid. Font Oporto (2014); Font Oporto (en prensa). 


\subsection{Fundamentación de la resistencia civil en Suárez}

Suárez no lleva a cabo en ningún pasaje una explicación clara y sistemática de los fundamentos de la resistencia a la tiranía, sino que es una cuestión que, dentro del orden y la lógica sistemática que él sigue (la del método escolástico de las questiones o disputationes), se trata de manera dispersa, incompleta e incluso a veces contradictoria. Lo mismo ocurre en relación con la limitación del poder en su teoría política. A lo largo de las páginas que dedica al tema de la resistencia al tirano, Suárez emplea distintos fundamentos de manera indistinta para justificarla, en ocasiones incluso de manera entreverada en el mismo párrafo.

Los más repetidos son la legítima defensa y la guerra justa; en menos ocasiones se alude al bien común, e incluso al incumplimiento por parte del príncipe del pacto original firmado con la comunidad.

Uno de los argumentos más reiterados es la legítima defensa ${ }^{49}$. Se trata esta de un derecho natural, tanto del sujeto individual como de la comunidad, que no puede ser enajenado ${ }^{50}$, lo cual llama la atención por cuanto, como ya se vio, Suárez sí admite que el poder político pueda ser transferido. En este sentido, la legítima defensa se halla por encima de cualquier posible transacción y es independiente de la entrega del poder, aun absoluta, por parte de la comunidad a un gobernante.

Por lo que respecta a la guerra justa como justificación de la resistencia e incluso de la rebelión abierta de la comunidad contra el rey tirano, es también un argumento muy reiterado ${ }^{51}$ que se basa en la respuesta legítima a una agresión injusta, lo que puede constatarse incluso en la combinación del mismo con el de la legítima defensa ${ }^{52}$.

En menos ocasiones, Suárez fundamenta también la posible resistencia al príncipe tiránico sobre un incumplimiento de los términos del contrato originario de traspaso del poder por parte de la comunidad, admitiendo la posibilidad de que ante dicho incumplimiento (o bien ante acciones contrarias al Derecho natural implícitamente prohibidas en dicho pacto), pueda la comunidad rescindir el contrato ${ }^{53}$.

49 Vid. Defensio fidei, VI, IV, 6, 9-11, 13 y 15; Defensio fidei, III, III, 3.

50 Cfr. Defensio fidei, VI, IV, 15.

51 Vid. De legibus, III, IV, 6; Defensio fidei, VI, III, 8; Defensio fidei, VI, IV, 6, 11, 13 y 19; Defensio fidei, VI, VI, 23-24. Por otro lado, cabe indicar que en ocasiones se alude al tirano por causa del mal gobierno como «invasor» (Defensio fidei, VI, IV, 5, 6 y 12). En cuanto al tirano usurpador, se habla de él como «un enemigo de la comunidad política [reipublicae]» (Defensio fidei, VI, IV, 7) y se le denomina también invasor (ibidem, 8).

52 Vid., por ejemplo, Defensio fidei, VI, IV, 6.

53 Vid. Defensio fidei, VI, VI, 11. Obsérvese que, igualmente, Suárez admite la posibilidad de que el pueblo intervenga en las decisiones políticas del rey en el supuesto de que dicho pueblo «al transmitirle el poder [...] se haya reservado» el poder "para algunos casos y asuntos más graves»; reserva que debe haberse recogido expresamente por escrito, o bien ha de obedecer a una costumbre asentada (Defensio fidei, III, III, 3). En Defensio fidei, VI, 


\subsubsection{Posible reducción al bien común de las distintas fundamentaciones de la} resistencia civil

Aunque el bien común es un argumento al que Suárez pocas veces se refiere explícitamente como fundamento de la resistencia, nuestra tesis es que de alguna manera cabe considerarlo como el elemento conceptual que aúna y sintetiza las diferentes argumentaciones que este autor emplea para fundamentar la resistencia civil a la tiranía en particular ${ }^{54}$. Entendemos que esa fundamentación de la aceptación (en determinados casos) de la resistencia civil no es casual y entronca directamente con el hecho de que el bien común es, en general, el cimiento y el objetivo de la teoría política de Suárez, e incluso de su Filosofía práctica en general.

En efecto, como ya se ha defendido, el bien común es en Suárez el fundamento del poder político, de la posible traslación del mismo al gobernante y de la obediencia a este último. Por tanto, se erige también en el límite primordial del ejercicio del poder por parte de dicho gobernante y, por tanto, de su teoría de los límites del poder político en general.

Ahora bien, hay que resaltar que el bien común actúa en el pensamiento político de Suárez no sólo como un límite teórico, sino también práctico o empírico: su asociación con la posibilidad de la oposición material de la comunidad contra el gobernante lo convierte en un concepto de gran valor en la praxis política.

En efecto, la posibilidad de que la acción material del pueblo (a través de los instrumentos no institucionalizados de la desobediencia, la resistencia o incluso la sublevación) sea legítima depende no sólo de que el poder institucionalizado esté conculcando el bien común, sino también de que

V, 4 Suárez había admitido la posibilidad de rescisión del pacto (y, consecuentemente del juramento y la debida obediencia al rey) mediante una intervención del papa en la que este ejerza su «potestad de liberar a los vasallos del rey herético o pernicioso para los súbditos cristianos».

54 En las escasas ocasiones en que Suárez alude al bien común para fundamentar la resistencia civil suele utilizarlo además como complemento o refuerzo de los demás fundamentos. Así, por ejemplo, para justificar la resistencia como legítima defensa, concretamente en el caso de actuación en «defensa de la propia comunidad [reipublicae defensione] [...] en el supuesto de que el rey esté atacando actualmente el país [civitatem] con la injusta intención de destruirlo y matar a sus ciudadanos o algo similar [vel quid simile]». En efecto, señala que «si está justificado ese procedimiento cuando se trata de defender la propia vida, mucho más a favor del bien común [multo magis pro communi bono]» (vid. Defensio fidei, VI, IV, 6). De ahí que aunque Suárez admita «una quasi alienatio de los derechos de la comunidad política» en favor del príncipe, defienda, sin embargo, que «esta suprema autoridad política es limitada, externa e internamente», pues «debe respetar las exigencias de la ley natural y del bien común, así como las del pacto de traspaso» (PACE (1993), p. 346). De otro lado, cabe subrayar que en la centralidad del bien común Suárez sigue la tradición escolástica y de la Escuela española del s. XVI. Sobre el tema del bien común en la Escuela de los juristas clásicos españoles puede consultarse Pereña Vicente (1950). 
dicha oposición material respete también y comporte como consecuencia una mejora del mismo. De este modo-y en esto Suárez es muy estrictodicha oposición popular no será legítima si es contraproducente para el bien de la comunidad. Al respecto, Suárez traza un matizado esquema de posibles situaciones en las que busca la justicia material del caso concreto, guiado siempre por el principio último del bien común, que es también el bien individual del ser humano como ser con naturaleza social ${ }^{55}$. Así, en Suárez el bien común es siempre la idea central que se toma como referencia para discernir cómo puede ser ejercida la resistencia, cuáles son sus necesarios límites y qué propósitos debe perseguir.

\subsection{El papel del derecho de resistencia en la teoría política de Suárez. La limitación fáctica del poder fundamentada en el bien común ${ }^{56}$}

A nuestro juicio, la importancia del bien común fáctico como fundamento del derecho la resistencia en Suárez es crucial para alcanzar una más adecuada comprensión del importante alcance del mismo en su teoría política. La resistencia, como última palabra del pensamiento político de Suárez, es el cierre de bóveda que da sentido a toda su construcción.

\subsubsection{La resistencia como límite del poder político. Límite fáctico, no institucio- nalizado y basado en el bien común}

Ya hemos defendido que en el pensamiento suareciano en general, y el político en particular, hay elementos medievales, modernos y otros que cabe adscribir a una Modernidad diferente, esto es, diversa a la hegemónica.

Sostenemos que, conforme a esos rasgos, la limitación del poder político en Suárez se produce a través de la primacía del bien común fáctico en el caso concreto. De este modo, Suárez establece de una manera no explícita ni directa un sistema de límites del poder político fácticos y no institucionales, integrado por aquellos frenos que, en la teoría de Suárez, y en orden a la consecución del bien común, pueden de facto oponerse al poder político por vías no jurídicoformales, bien sea por la propia comunidad política, bien sea por un miembro de la misma ${ }^{57}$. El corazón de ese sistema son la desobediencia y la resistencia

55 Debe tenerse en cuenta que en Suárez el bien común tiene absoluta prevalencia como criterio orientador de las acciones emprendidas contra la posible tiranía del gobernante. Así, por ejemplo, Suárez impone como condición que permite considerar legítimo el tiranicidio del usurpador la de que no «se tema que de la muerte del tirano van a resultar para la comunidad política [reipublicae] los mismos o mayores males que los que sufre bajo la tiranía» (Defensio fidei, VI, IV, 9). Vid. también Defensio fidei, VI, IV, 5).

56 En este punto reelaboramos nuestras tesis ya defendidas en Font OpORTo (2013a), pp. 513-518.

57 Los únicos límites institucionales al poder político que Suárez prevé son los que puede ejercer el papa. Ahora bien, el núcleo de los límites del poder en la teoría política suareciana no es institucional. 
civil, que pueden ejercerse en determinados supuestos concretos y con determinados requisitos ${ }^{58}$.

De este modo, si bien Suárez sostiene expresamente que, en principio, la entrega del poder es irrevocable y «no puede privarse al rey de ese poder», sin embargo, si el rey se convierte en tirano «puede el pueblo [regnum] emprender contra él una guerra justa», es decir, la resistencia activa ${ }^{59}$. Por tanto, si bien, como se vio, parece que Suárez admite una enajenación total del poder en manos de un rey absoluto, puede afirmarse, sin embargo, que en caso de tiranía puede el pueblo emplear una serie de instrumentos que de facto limitan el poder del gobernante e incluso pueden privarle del mismo ${ }^{60}$.

\subsubsection{La resistencia como abertura hacia una democracia directa fáctica, distinta del modelo hegemónico moderno de democracia representativa liberal}

Como se aprecia de lo expuesto, en el ir y venir de excepciones y contraexcepciones de la teoría política de Suárez, el resultado final permite a la comunidad ejercer el control del poder, precisamente a través de algo tan peculiar como es el derecho de resistencia al tirano, legitimado con el derecho básico a la legítima defensa, propia y de la comunidad. Se constata, por tanto, que la conclusión final de la teoría política de Suárez es que la resistencia civil tiene la última palabra en la misma y, con toda la excepcionalidad que se quiera, es una herramienta que, a modo de inquebrantable martillo, puede destrozar toda la construcción erigida en su teoría del poder. Ahora bien, de aquí se deduce que, de alguna manera, y por la vía de los hechos más desnudos, en Suárez se abre una puerta a la democracia. Una democracia directa no institucionalizada que emerge en momentos puntuales y tasados, que irrumpe violentamente y (en cierto modo) sin orden, a borbotones, si se permite la expresión. Además,

58 Dicho de otro modo: si el rey se convierte en un tirano, los miembros de la comunidad política pueden legítimamente (y según los diferentes supuestos) llevar a cabo una batería de acciones que van desde la mera desobediencia o resistencia pasiva hasta la resistencia activa, el levantamiento (mediante una guerra justa) contra el rey, el enjuiciamiento del rey tirano por la comunidad, su deposición o expulsión, e incluso su occisión.

59 De legibus, III, IV, 6.

60 De esta forma, conserva también el pueblo un derecho a resistir como ejercicio del derecho a la legítima defensa, de modo que queda de alguna manera desactivada la monarquía absoluta. En este sentido, afirma Suárez que «la comunidad política en su totalidad [tota respublica] podría levantarse contra» el tirano mal gobernante, "y entonces no se levantará propiamente en sedición [...]. La razón se debe a que entonces la comunidad política en su totalidad [tota respublica] es superior al rey, pues habiéndole dado a él su poder, se cree que se lo dio con la condición de que gobernara políticamente, no tiránicamente; de lo contrario [dicho rey] podría ser depuesto por la misma [comunidad política]» (De bello, VIII, 2; traducción propia a partir de Pereña Vicente (1954), pp. 239-241 y Pereña Vicente (1975), p. XIX). Esta frase concuerda con la afirmación suareciana de que la comunidad nunca renuncia a su derecho natural a defenderse a sí misma (cfr. Defensio fidei, II, III, 3). Al respecto, sostiene Pereña Vicente que para Suárez, «aun en el caso extremo de la monarquía absoluta, el pueblo nunca ha renunciado a su derecho a un gobierno justo» (Pereña Vicente (1975), p. LXXIV). 
y esto es crucial, esa actuación directa del pueblo sólo queda legitimada en ciertos casos si quedaran acreditados ciertos requisitos: unos y otros quedan compendiados en la idea del bien común fáctico y concreto ${ }^{61}$.

En este sentido, ya hemos defendido que la facticidad política suareciana alcanza aquí en muchas ocasiones posibilidades fácticas irrealizables desde la perspectiva propia de gran parte de las ideologías políticas modernas ${ }^{62}$. Estas se encuentran muchas veces centradas en una institucionalidad idealizada desde una razón instrumental que niega en ocasiones sus propios fracasos en la realidad, bien afirmando cínicamente la propia necesidad racional de los mismos, bien remitiéndolos en su solución a un futuro utopizado que encubre, por la vía de la sublimación, situaciones contrarias a la dignidad humana. En efecto, cabe apreciar que la rigurosa doctrina de la resistencia al poder que Suárez elabora podría tener una importante virtualidad desde la realidad sociopolítica concreta que a este autor le toca vivir. En particular, en cuanto concierne a admitir una posibilidad material y auténtica de imponer límites a los desmanes del poder y someterlo a cierto control por parte de la comunidad.

Las virtualidades de los rasgos del enfoque de Suárez, en el que junto a lo medieval existen elementos de una Modernidad diferente, suponen que, en muchas cuestiones, se supere los estrechos límites del concepto democrático liberal representativo propio de la Modernidad hegemónica occidental. Una muestra particularmente significativa de esta singularidad queda manifestada en lo que podríamos denominar la facticidad democrática manifestada en su teoría sobre el derecho de resistencia.

Por tanto, sostenemos que el pragmatismo fáctico de Suárez (que busca la realización concreta de la justicia por encima del diseño teórico de instituciones perfectas pretendido por el liberalismo) le permite reconocer como posible la entrega absoluta e irrevocable del poder en función de la realización del objetivo supremo, el bien común. Y, de modo concorde, la preeminencia plena de esa finalidad obligaría a aceptar la posibilidad de oponerle resistencia o deponerlo cuando la actuación del gobernante no se desarrolla en aras a la realización efectiva del mencionado bien común.

\section{Conclusiones}

Si retomamos la hipótesis inicial de este trabajo, ha podido constatarse, a nuestro juicio, que en la teoría política de Suárez existen aspectos modernos, pero también otros relacionados con una Modernidad diferente, junto con algunos aún medievales. Así lo apreciamos en temas tales como las relaciones

61 Pereña Vicente subraya que en Suárez «se obedece al gobernante en todo aquello que se orienta a la realización del bien común y en las condiciones y con las limitaciones que fueron señaladas en la transmisión del poder». Por tanto, «la obediencia civil no adquiere [...] un valor absoluto: en cierto modo se relativiza en virtud del dinamismo del bien común y de la voluntad popular» (Pereña Vicente (1975), pp. LXXI-LXXII).

62 Vid. Font Oporto (2013a), p. 518. 
sociales naturales, el origen social del poder y el modo de causación del mismo por resultancia natural, la necesidad de la existencia del poder político en orden a la consecución del bien común, la organización del poder político y la entrega del poder al gobernante en aras del bien común (entrega que se entiende irrevocable sobre la base del mismo argumento), o la posibilidad de resistencia en pro también del bien común (con determinados requisitos, excepciones y contra-excepciones).

Es claro que en todas estas cuestiones están presentes rasgos eminentemente modernos, por ejemplo, el amplio margen de acción que la filosofía política de Suárez deja a la capacidad de la voluntad humana. Por otro lado, hay también elementos medievalizantes, tales como la preferencia por la monarquía como forma de gobierno, la anacrónica metáfora de la esclavitud voluntaria, o la propia aceptación de figuras no jurídico-formales como la resistencia. Por lo que respecta a la valoración de la facticidad del caso concreto (el atenerse a los hechos y circunstancias de la realidad y actuar de manera acorde con la misma) hay aquí elementos en los que pueden apreciarse vínculos con lo que hemos dado en llamar Modernidad diferente, y que no pueden resumirse en etiquetas reduccionistas tales como la de "casuista» o "probabilista». La conjunción de esta facticidad con la centralidad del bien común (concepto con rasgos también parcialmente medievales) en toda la filosofía práctica suareciana es, a nuestro entender, la palanca que mueve a Suárez en su análisis y tratamiento de los casos concretos en el ámbito político.

Esta es la razón que explica por qué la resistencia como límite fáctico del poder político se erige en la llave que, a modo de círculo, cierra sus tesis políticas. Es decir, la consecución del bien común en las específicas circunstancias de cada caso concreto es el objetivo capital que conduce a Suárez a aceptar la resistencia y el tiranicidio en orden a la preservación de aquel. Lo que significa, en última instancia, que el bien común del caso concreto se antepone al poder político. E incluso, más allá de esa interpretación, cabría sostener que la resistencia civil constituye en Suárez una vía de participación política directa y no institucionalizada del pueblo que, en cierto modo, podría considerarse radicalmente democrática y encarnada en la facticidad de la realidad concreta del momento ${ }^{63}$. Eso sí, siempre subordinada a la consecución del bien común.

\section{BiBLIOGRAFÍA}

\section{A. Fuentes directas o primarias:}

Defensio fidei catholicae et apostolicae adversus anglicanae sectae errores, cum responsione ad apologiam pro iuramento fidelitatis et praefationem monitoriam serenissimi Iacobi Angliae regis. Authore P. D. Francisco Suario Granatensi e Societate Iesu. Conimbricae: apud Didacum Gomez de Loureyro academiae typographum, 1613.

63 Ya hemos desarrollado más ampliamente esta visión en Font OpORTo (2013a) y FonT OpORTo (2014), capítulo quinto. 
Edición manejada del Libro III de la Defensio fidei:

Suárez, F. (1965). Principatus politicus (Defensio fidei III. I. Principatus politicus o la soberanía popular). Madrid: Consejo Superior de Investigaciones Científicas.

Edición manejada del Libro VI de la Defensio fidei:

SuÁrez, F. (1978). De iuramento fidelitatis. Documentación fundamental. Madrid: Consejo Superior de Investigaciones Científicas.

Tractatus De legibus ac Deo legislatore in decem libros distributus. Authore P. D. Francisco Svarez Granatensi e Societate Iesu, Sacra Teheologiae, in celebri Conimbricensi Academia Primario Professore. Ad Illustrissimum et Reverendissimum D. Alphonsum Furtado de Mendoça Episcopum Egitaniensem. Cum variis indicibus. Conimbricae. Cum Privilegio Regis Catholici Pro Castella et Lusitania. Apud Didacum Gomez de Loureyro. Anno Domini 1612.

Edición manejada del Libro I:

SuÁrez, F. (1971). De Legibus, vol. I [1ª mitad del Libro I]. Madrid: Consejo Superior de Investigaciones Científicas.

Edición manejada del Libro III:

SuÁrez, F. (1975). De Legibus, vol. V [1 $1^{\text {a }}$ mitad del Libro III]. Madrid: Consejo Superior de Investigaciones Científicas.

\section{B. Fuentes indirectas o secundarias:}

AA.VV. (n.d.). «ElorduY, Eleuterio.» Recuperado de http://www.saavedrafajardo. org/CentroDocumDiazAbad.aspx?autor=ELORDUYEleuterio\&idAutor $=1009214$ [consulta: 28-05-2017].

Abril Castelló, V. (1978). «La acción de resultancia, eje de rotación del sistema suareciano». En P. Rocamora Valls, F. Rodríguez, y J. Iturriaga (Eds.), Homenaje a Eleuterio Elorduy SJ (pp. 1-10). Bilbao: Universidad de Deusto.

Amezúa Amezúa, L.-C. (2008). «La libertad cuestionada: justificación de la esclavitud en la segunda escolástica». En AA.VV. (Ed.), Estudios en homenaje al profesor Gregorio Peces-Barba, vol. IV (pp. 53-70). Madrid: Dykinson.

Barroso Fernández, O. (2008). "La metafísica de Suárez en la filosofía barroca». En A. J. Morales (coord.), Congreso Internacional Andalucía Barroca: actas, Iglesia de San Juan de Dios de Antequera, 17-21 de septiembre de 2007; vol. 4 (pp. 17-26). Sevilla: Junta de Andalucía.

Calafate, P. y Mandado Gutiérrez, R. E. (2014). «Introducción». En P. Calafate y R. E. Mandado GutiérRez (Dirs.), Escuela ibérica de la paz. Santander: Universidad de Cantabria, 110-155.

Cabral de Moncada, L. (1948). "O vivo e o morto em Suárez jurista». En Actas del IV Centenario de Francisco Suárez, 1548-1948, tomo II (pp. 225-241). Madrid: Dirección General de Propaganda.

Domingues, B. H. (1997), "O Medieval e o Moderno no Mundo Ibérico e IberoAmericano». Revista Estudos Históricos, 10 (20), 195-216.

Dussel, E. (2007a). Materiales para una política de la liberación. México D.F. - Madrid: Universidad Autónoma de Nuevo León-Plaza y Valdés.

- (2007b). Política de la liberación: historia mundial y crítica. Madrid: Trotta.

Elorduy, E. (1952). «Orientaciones en la interpretación de las doctrinas jurídicas de Suárez». Revista de Estudios Políticos, (66), 77-110.

- (1963). «La acción de resultancia en Suárez». Anales de La Cátedra Francisco Suárez, (3), 45-71. 
Font Oporto, P. (2013a). «El núcleo de la doctrina de Francisco Suárez sobre la resistencia y el tiranicidio». Pensamiento: Revista de Investigación e Información Filosófica, 69 (260), 493-521.

- (2013b). «El enfoque político pragmático-fáctico de Francisco Suárez. De las soluciones ideológicas modernas al bien común concreto y no institucional». En Simposio UNIJES de Pensamiento Social Cristiano "Propuestas en tiempos de crisis». Actas electrónicas (55-58). Sevilla: Universidad Loyola Andalucía. Disponible en https:/www.uloyola.es/ftp/documentos/departamentos/ACTAS_ELECTRONICAS. pdf [consulta 3-6-2017].

- (2014). Limites de la legitimidad del poder político y resistencia civil en Francisco Suárez (tesis doctoral). Universidad de Sevilla, Sevilla. Disponible en http://fondosdigitales. us.es/tesis/tesis/2535/limites-de-la-legitimidad-del-poder-politico-y-resistencia-civilen-francisco-suarez/ [consulta: 27-4-2017]

- (2017a). «Obediencia y desobediencia a reyes herejes y no cristianos en Francisco Suárez. Potestad del papa al respecto». Gregorianum, 98 (1), 61-74.

- (2017b). «Tipos de tirano y resistencia en Francisco Suárez». Anales de la Cátedra Francisco Suárez, (51), 183-207.

- (en prensa). «La Metafísica como eje de sistematización del pensamiento político de Francisco Suárez». En Actas del Congreso Mundial de Metafísica.

PACE, P. (1993). «Los límites de la obediencia civil en el Siglo de Oro: Francisco Suárez». En Ética y Teología ante el Nuevo Mundo: Valencia y América: actas del VII Simposio de Teología Histórica (28-30 abril 1992) (pp. 341-350). Valencia: Facultat de Teología San Vicente Ferrer.

Pereña Vicente, L. (1950). Hacia una sociología del bien común (el bien común en los juristas clásicos españoles). Madrid: Asociación Católica Nacional de Propagandistas.

- (1954). Teoría de la guerra en Francisco Suárez, vol. II («Texto crítico»). Madrid: Consejo Superior de Investigaciones Científicas.

— (1975). «Génesis suareciana de la democracia». En F. SuÁrez (Ed.), De Legibus, vol. V (pp. XVII-LXXVIII). Madrid: Consejo Superior de Investigaciones Científicas.

Pérez Espigares, P., Font Oporto, P., Senent de Frutos, J. A. y Sepúlveda del Río, I. (en prensa). «Resultant Action and the Modern Character of Suarez's Metaphysics». Review of Metaphysics.

RÁbade, S. (1997). Francisco Suárez (1548-1617). Madrid: Ediciones del Orto.

Rosillo Martínez, A. (2011). Los inicios de la tradición iberoamericana de los derechos humanos. Aguascalientes-San Luis Potosí: Universidad Autónoma de San Luis Potosí - CENEJUS.

Scannone, J. C. (1999). «Lo social y lo político según Suárez. Hacia una relectura latinoamericana actual de la filosofía política de Suárez». En J. C. Scannone y V. SANTUC (Eds.), Lo político en América Latina. Desafíos actuales. Contribución filosófica a un nuevo modo de hacer política (pp. 239-380). Buenos Aires: Bonum.

Schwartz Porzecanski, D. (2005). «Francisco Suárez y la tradición del contrato social». Contrastes: Revista Internacional de Filosofía, (10), 119-138. Recuperado de http:// www.uma.es/contrastes/pdfs/010/VOLX-7-Schwarzt_Porzecanski.pdf

Senent de Frutos, J. A. (2010). «La función de la universidad en el pensamiento de Ignacio Ellacuría. Una visión desde nuestro contexto». Revista de Fomento Social, (260), 657-679.

- (2014). «Hacia una relectura de la matriz cultural ignaciana desde nuestras necesidades civilazatorias actuales». Concordia. Internationale Zeitschcrift für Philosophie, 66, 25-48. 
- (2017). «Ignatian Modernity as another Kind of Modernity». En Schelkshorn, H. y Westerink, H. (Dirs.), Reformation(en) und Moderne (pp. 153-172). Viena: V\&R unipress.

Universidad Loyola Andalucía

Pablo Font Oporto

pfont@uloyola.es

[Artículo aprobado para publicación en enero de 2018] 